\title{
Management of Diabetic Retinopathy. An Overview
}

\author{
Eustratios V. Gotzaridis ${ }^{1}$, Athina Markou ${ }^{2}$, Zdenek Gregor ${ }^{3}$
}

\begin{abstract}
${ }^{1}$ Eye Department, Athinaiki General Hospital, Athens, Greece, ${ }^{2}$ Department of Endocrinology, G. Genimatas General Hospital, Athens, Greece, ${ }^{3}$ Medical Retina Department at Moorfields Eye Hospital, London EC1V 2 PD, UK.
\end{abstract}

\section{INTRODUCTION}

Patients with type 1 diabetes mellitus experience a high incidence of severe ocular complications and are more likely to have significant ocular problems during their lifetimes. Patients with type 2 diabetes mellitus (DM2), however, make up the majority of clinical cases with diabetic eye disease because of the higher incidence of DM2.

Diabetic retinopathy is a highly specific vascular complication of both type 1 and type 2 diabetes mellitus. It remains one of the commonest causes of visual loss in people of working age in developed countries. Both duration of diabetes and glycaemic control are significant risk factors for the development of retinopathy. After 20 years of diabetes, nearly all patients with type 1 diabetes mellitus, and more than $60 \%$ of patients with type 2 diabetes mellitus, have some degree of retinopathy. Although at present there is no known cure for diabetic retinopathy and diabetic macular oedema, laser surgery and other therapeutic modalities help minimize the risk of mild and severe visual loss from these conditions and, in some cases, restore useful vision for those patients who have suffered significant visual loss. These therapeutic modal-

Key words: Diabetic retinopathy, Laser, Vitrectomy

Address correspondence and requests for reprints to: Eustratios V. Gotzaridis, MD, V. Sophias \& 4 Kerassountos Str, Athens 115 28, Greece, Tel. +30 2107711 320, Fax. +30 2109811345 , e-mail: eugotzi@yahoo.com

Received 26-11-03, Revised 26-02-04, Accepted 10-03-04 ities, particularly laser treatment, are most effective when initiated at the time a person is at high-risk for proliferative diabetic retinopathy or before visual acuity is lost from diabetic macular oedema ${ }^{1}$.

The 5-year risk of severe visual loss from untreated high-risk proliferative diabetic retinopathy may be as high as $60 \%$, and the risk of mild visual loss from diabetic macular oedema may be as high as 25 to $30 \%$. Since proliferative diabetic retinopathy and diabetic macular oedema may cause no ocular or visual symptoms when the retinal lesions are most amenable to treatment, the overriding concern is to identify eyes at risk of visual loss and ensure that the patients receive referral for laser surgery at the most appropriate time. Even minor errors in diagnosing the level of retinopathy can result in a significant increase in a person's risk of visual loss.

Furthermore, collateral health and medical problems present a significant risk for the development and progression of diabetic retinopathy. These factors include pregnancy ${ }^{2-4}$, chronic hyperglycaemia ${ }^{5-8}$, hypertension $^{9}$, renal disease ${ }^{7}$, hyperlipidemia ${ }^{10,11}$ and cardiovascular autonomic neuropathy ${ }^{12}$. Patients with these conditions require careful medical evaluation and follow-up for identification of diabetic retinopathy.

\section{DIAGNOSIS AND CLASSIFICATION OF DIABETIC RETINOPATHY}

Diabetic retinopathy is broadly classified as nonproliferative diabetic retinopathy and proliferative diabetic retinopathy (Table 1). Diabetic macular oedema can occur with either non-proliferative diabetic 
Table 1. Classification of retinal lesions of diabetic retinopathy.

\begin{tabular}{l} 
A. Non-proliferative (Background diabetic retinopathy) \\
Microaneurysms \\
Intraretinal haemorrhages \\
Hard exudates \\
B. Pre-proliferative diabetic retinopathy \\
Intraretinal microvascular abnormalities (IRMAs) \\
Venous dilatation, venous beading, loop formation \\
Soft exudates (Cotton-wool spots) \\
Deep round haemorrhages \\
C. Proliferative diabetic retinopathy \\
Neovascularization at the optic disc \\
Neovascularization elsewhere at the retina \\
Preretinal haemorrhage or vitreous haemorrhage \\
Preretinal fibrosis \pm tractional retinal detachment \\
\hline
\end{tabular}

retinopathy or proliferative diabetic retinopathy (background diabetic retinopathy) and is discussed separately.

A precise definition of a patient's "diabetic retinopathy level" is critical because there is a varying risk of progression to proliferative diabetic retinopathy depending on the specific non-proliferative "diabetic retinopathy level".

The first clinical signs of diabetic retinopathy are microaneurysms, which are saccular outpouchings of retinal capillaries (Figure 1). Ruptured microaneurysms, decompensated capillaries and intraretinal microvascular abnormalities (IRMAs) result in intraretinal haemorrhages. Hard exudates are depositions of lipid-rich proteins within the retina after the breakdown of the blood-retinal barrier.

Intraretinal microvascular abnormalities (Figure 2) represent either new vessel growth within the retina or, more likely, pre-existing vessels with endothelial cell proliferation that become "shunts" through areas of nonperfusion. IRMAs may be seen adjacent to soft exudates (cotton-wool spots). Multiple IRMAs mark a severe stage of non-proliferative diabetic retinopathy, and frank neovascularization is likely to appear on the surface of the retina or optic disc within a short time.

Venous calibre abnormalities are indicators of severe retinal hypoxia. These abnormalities can be venous dilatation, venous beading, or loop formation.

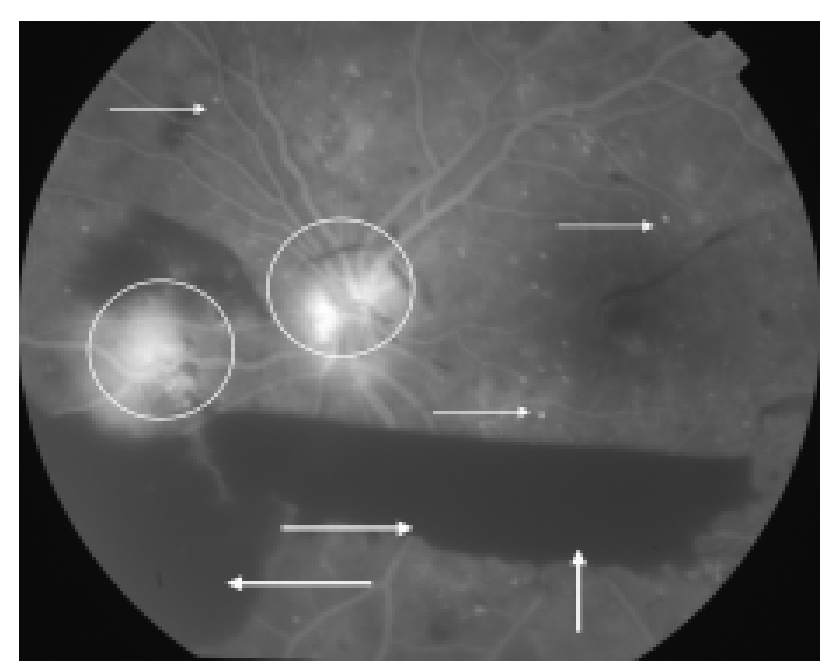

Figure 1. A black-white picture of an eye during Fluorescein angiography. The fluorescent background is blocked by an inferior vitreous haemorrhage (mask effect) (large arrows). Small bright white spots all around the fundus represent microaneurysms that gather the flourescein dye and fluorescent more than surrounding tissues (small arrows). New vessels on the disc and the periphery leak the fluorescein dye to the vitreous cavity (white circles).

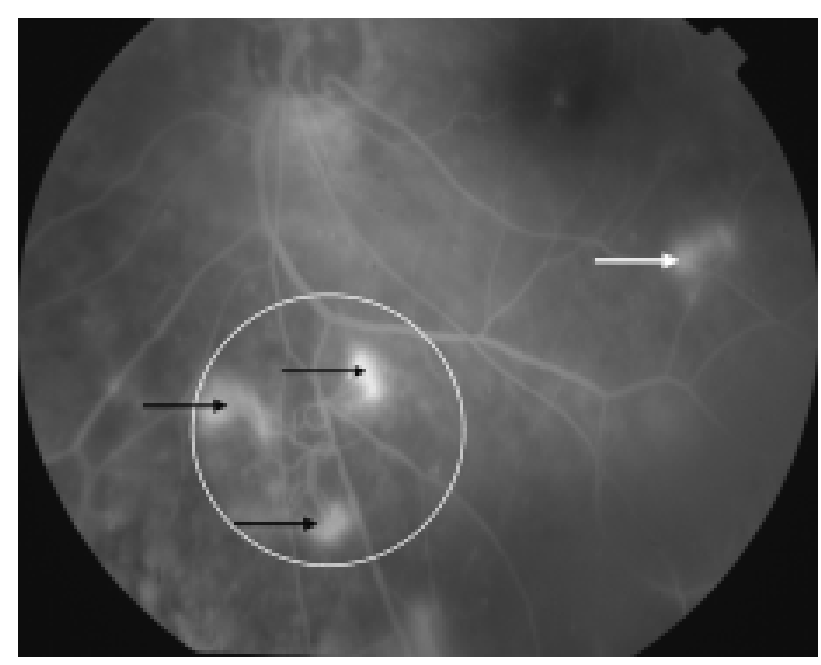

Figure 2. Fluorescein angiography of a diabetic fundus with intraretinal microvascular abnormalities (IRMAs) (white circle) that leak (black arrows). New vessels that also leak are seen at the periphery (white arrow).

There are often large areas of nonperfusion adjacent to these veins. Cotton-wool spots are fluffy white spots in the inner retina that represent infarcts of the nervefibre layer.

Proliferative diabetic retinopathy is marked by proliferating endothelial cell tubules. The rate of 
growth of these new vessels is variable and they grow either at or near the optic disc (neovascularization of the disc) (Figures 3a, 3b) or elsewhere in the retina (neovascularization elsewhere) (Figures 1, 2). Translucent fibrous tissue often appears adjacent to the new vessels. This fibroglial tissue appears opaque and becomes adherent to the adjacent vitreous.

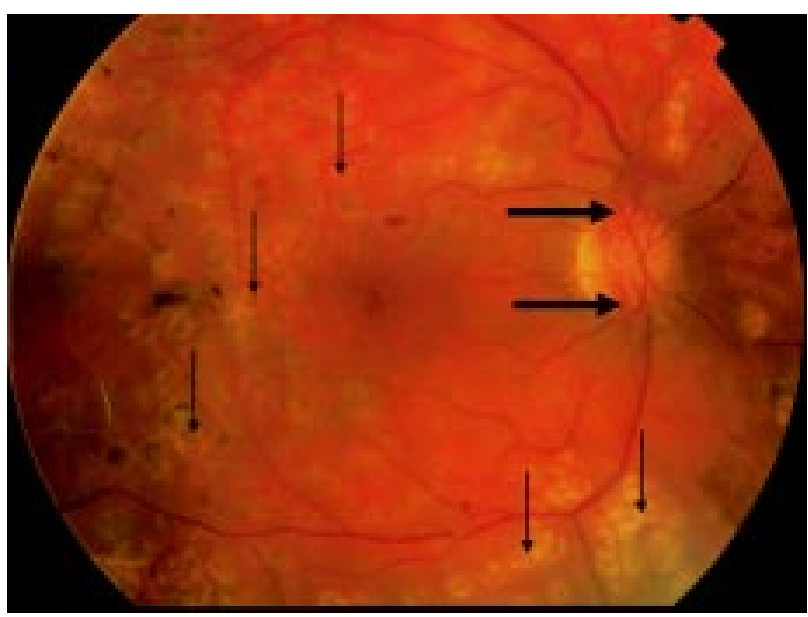

Figure 3a. Colour fundus picture of an eye with Proliferative Diabetic Retinopathy. Neovascularisation of the disc together with fibrin tissue (large arrows) shows a not well-controlled diabetic eye disease due either to a late start of the panretinal laser photocoagulation [yellowish spots with dark center (small arrows)], or to insufficient laser treatment during the therapy sessions. This eye needs additional laser treatment.

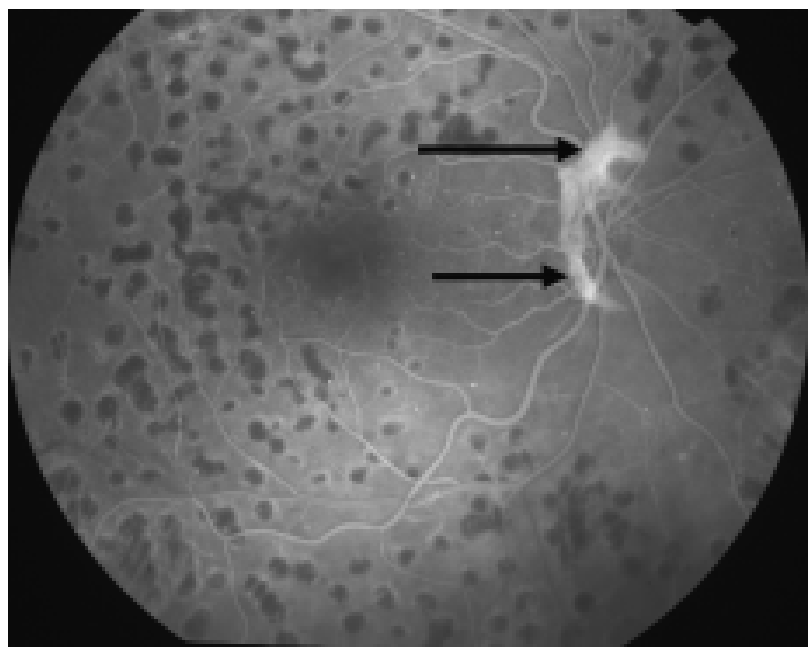

Figure 3b. With a fluorescein angiography, the neurovascularisation of the disk is more evident (arrows). Black spots represent the laser scars.

\section{DIABETIC MACULAR OEDEMA}

Diabetic macular oedema may be present at any level of retinopathy and alters the structure of the macula, significantly affecting its function. Lesions of diabetes on the macula include:

1. Macular oedema, i.e., a collection of intraretinal fluid in the macula with or without lipid exudates and with or without cystoid changes.

2. Nonperfusion of parafoveal capillaries with or without intraretinal fluid.

3. Traction in the macula by fibrous tissue proliferation causing dragging of the retinal tissue, surface wrinkling or detachment of the macula.

4. Intraretinal or preretinal haemorrhage in the macula.

5. Lamellar or full-thickness retinal hole formation.

6. Any combination of the preceding.

\section{THE ROLE OF FLUORESCEIN ANGIOGRAPHY IN THE DIAGNOSIS AND CLASSIFICATION OF DIABETIC RETINOPATHY}

Fluorescein angiography of the macula in the presence of diabetic macular oedema is fundamental for the detection of treatable lesions. However, its use to identify lesions such as neovascularization elsewhere or neovascularization of the disc is not necessary, since such lesions should be clinically evident.

Although abnormalities detected by fluorescein angiography provide additional prognostic information, the colour fundus photographic grading of retinopathy levels of both eyes gives the same prognostic results ${ }^{13,14}$. Therefore, the increase in power to predict progression from non-proliferative diabetic retinopathy to proliferative diabetic retinopathy by fluorescein angiography is "not of significant clinical importance to warrant routine fluorescein angiography"14.

Periodic follow-up retinal examinations, however, are absolutely necessary. The retinal level of diabetic retinopathy derived from colour fundus photography is predictive enough to establish frequency of followup, whereas fluorescein angiography classification cannot identify all cases destined to progress. Initiation of scatter (panretinal) laser photocoagulation 
should be considered as diabetic retinopathy approaches (before or just as it reaches) the high-risk stage. Hence "periodic follow-up of all patients with diabetic retinopathy continues to be of fundamental clinical importance" ${ }^{14}$.

Optical Coherent Tomography (OCT) is a new imaging technique that provides more adequate information for the early diabetic macular oedema. The current standard of care for early diabetic macular oedema detection, slit-lamp examination of the fundus, is less sensitive than OCT for detection of the oedema. Therefore, OCT may be beneficial in early detection and treatment of early diabetic macular oedema $^{15-17}$.

\section{MANAGEMENT OF DIABETIC RETINOPATHY}

\section{Argon laser photocoagulation}

It is crucial to consider scatter (panretinal) laser surgery as retinopathy approaches or reaches the highrisk stage of proliferate retinopathy. An eye is considered to be approaching the high-risk stage when there are retinal signs of severe or very severe nonproliferative diabetic retinopathy, with or without new vessels, or extensive new vessels, not fulfilling the definition of high-risk retinopathy associated with any level of non-proliferative diabetic retinopathy.

Two or more sessions of scatter laser photocoagu- lation will provide stabilisation and regression of the lesions at this stage. Every laser session includes seven to eight hundred laser spots in a scatter mode at the mid-retinal periphery ${ }^{13}$.

The baseline level of retinopathy indicates the risk of progression from the non-proliferative diabetic retinopathy stage to early proliferative diabetic retinopathy and to high-risk proliferative diabetic retinopathy. At this stage an extensive laser photocoagulation should be applied in multiple sessions all around the retinal periphery in order to eliminate the retinal damages and visual loss ${ }^{1}$.

Focal laser surgery for diabetic macular oedema consists of either direct laser treatment or grid laser treatment, or a combination of direct laser to focal leaks and grid laser treatment to diffuse leakage or thickened avascular zones.

\section{Vitrectomy for proliferative diabetic retinopathy}

Standard laser cannot be performed in eyes with vitreous haemorrhage precluding visualization of the retina (Figures. 4a, 4b).

Removing dense, nonclearing vitreous haemorrhage remains an important indication for vitrectomy in diabetics ${ }^{18}$.

Progressive fibrovascular proliferation in diabetes

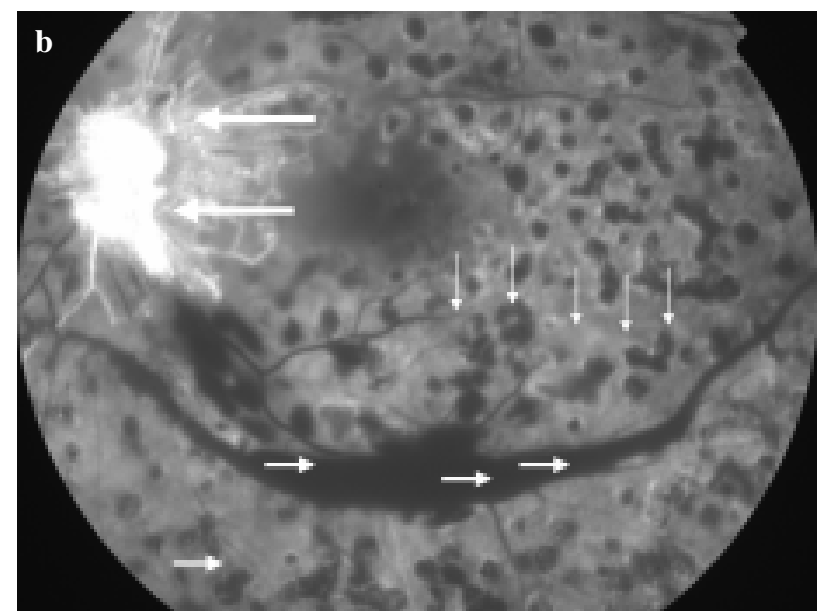

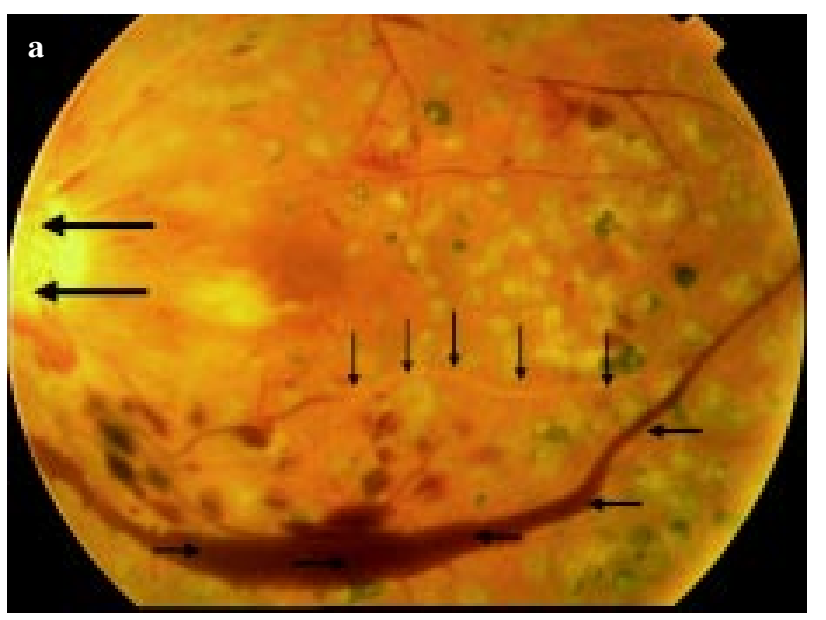

Figures $4 \mathbf{a}$ and $\mathbf{4 b}$. Colour fundus picture and fluorescein angiography (FA) picture of an eye with more advanced proliferative diabetic retinopathy and mild absorbing vitreous haemorrhage (small arrows), neurovascularisation of the disk (large arrows) and block retinal vessels due to endothelial cell pathology (vertical arrows). This vessel appears white in contrast with the red colour of the functioning retinal vessels. The same vessel does not show in the FA picture. The vessel is blocked and does not allow the blood to pass through the vessel (vertical arrows). 


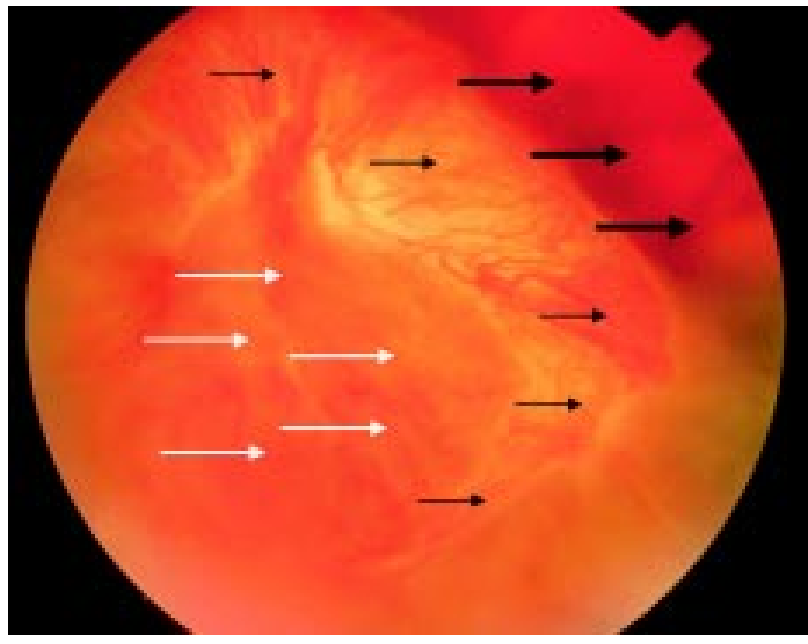

Figure 5. Very severe proliferative diabetic retinopathy with vitreous haemorrhage (large arrows), a huge fibrovascular membrane (small arrows) that causes traction retinal detachment (white arrows).

can lead to traction retinal detachment (Figure 5). Surgery should be performed promptly because degenerative changes in the detached retina will prevent visual recovery after reattachment (Figure 6). Vitrectomy can also be beneficial in the management of the macular oedema.

The goals of vitrectomy in diabetic retinopathy are simple in concept. One major objective is to remove media opacities, either vitreous haemorrhage or cataract. The second objective is to relieve vitreous trac-

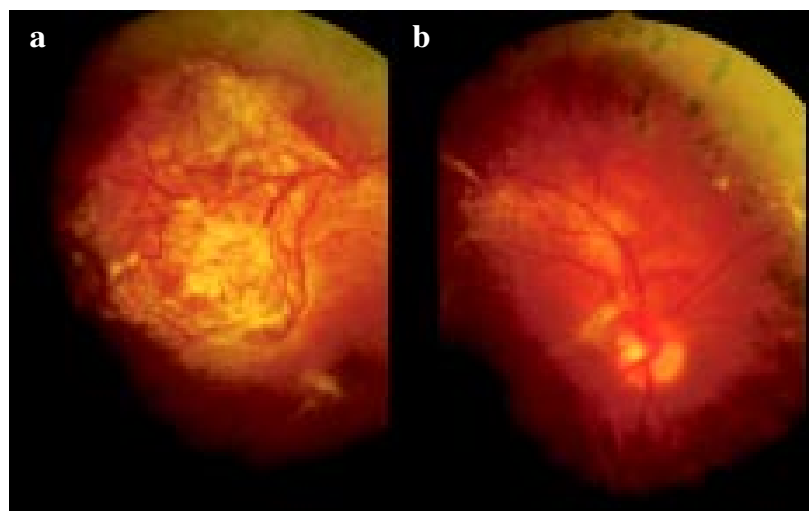

Figure 6. Traction retinal detachment involving the fovea. a. Preoperative photograph illustrates extensive neovascularization emanating from the disc with traction detachment. Visual acuity is 20/400. b. Postoperative photograph after vitrectomy shows retinal reattachment and removal of neovascular tissue. Visual acuity is 10/40. tion causing detachment, distortion or displacement of the fovea, either transvitreal traction from anterior vitreous to posterior attachments or tangential traction from proliferative tissue adherent to the retinal surface $^{17,19}$. As dissection is performed, it is important to obtain haemostasis to preserve visualization and allow for effective endophotocoagulation. The final goal is to perform retinal ablation, usually by laser, to prevent subsequent neovascular proliferation ${ }^{19}$.

Vitrectomy and peeling of the internal limiting membrane of the retina at the macular area has been proved beneficial in the management of the diabetic macular oedema. The main objective here is to relieve the traction of the internal limiting membrane on the macular area leaving the retinal tissue free to settle and absorb the oedema ${ }^{20,21}$.

Recent studies have shown that the use of Triamcinolone acetonide (TA) during the vitrectomy, or even as an intravitreal injection alone, provides a shortterm regression of the oedema and improvement of the vision. Intravitreal injection of TA after six months or less provides a prolonged beneficial improvement of the vision ${ }^{22,23}$.

This review has concentrated on the ophthalmologist's approach in the management of diabetic retinopathy. Nevertheless, it must be stressed that different medical modalities have also given encouraging results.

\section{PREVENTION OF RETINOPATHY}

The Diabetes Control and Complications Trial $(\mathrm{DCCT})^{24}$ and the United Kingdom Prospective Diabetes Study (UKPDS) ${ }^{25,26}$ demonstrated the beneficial effect of tight control of glycaemia and blood pressure on the development and progression of retinopathy.

Thus, the DCCT study showed an association between glycaemia and the progression of microvascular complications in patients with type 1 diabetes. In the primary-intervention cohort, intensive therapy reduced the adjusted mean risk of the onset of retinopathy by $76 \%$ during the course of the study, as compared with the conventional therapy. The reduction in risk increased with time. In the secondary-intervention cohort, the patients in the intensive-therapy group had a higher cumulative incidence of sustained 
progression of retinopathy by three steps or more during the first year than did those in the conventional-therapy group, but a lower cumulative incidence beginning at 36 months and continuing for the rest of the study. Intensive therapy reduced the average risk of such progression by $54 \%$ during the entire study period. Intensive therapy reduced the adjusted risk of proliferative or severe non-proliferative retinopathy by $47 \%(\mathrm{P}=0.011)$ and that of treatment with photocoagulation by $56 \%(\mathrm{P}=0.002)$.

The UKPDS assessed the effect of tight glycaemic control and blood pressure control on diabetic complications in type 2 diabetic patients. It showed that each $1 \%$ reduction in haemoglobin $\mathrm{A}_{1 \mathrm{c}}$ was associated with a $37 \%$ decrease in the risk for microvascular complications (nephropathy, retinopathy, neuropathy). No threshold of glycaemia was observed for a substantive change in risk for any of the clinical outcomes examined. The lower the glycaemia, the lower the risk of complications. The study also showed that tight blood pressure control reduced the risk of progression of diabetic retinopathy by $34 \%$ and deterioration in visual acuity by $47 \%$, suggesting that tight blood pressure control prevented the development of diabetic maculopathy which is the main cause of visual impairment in type 2 diabetes.

These studies emphasize the need for optimal, persistent diabetic control of patients with type 1 and type 2 diabetes.

\section{PERSPECTIVES}

Exciting developments have been achieved in the understanding of the underlying causes of vasoproliferative retinopathy and macular oedema. In 1948, Michaelson and colleagues postulated that retinal ischaemia activated a vasoproliferative factor in the retina, resulting in proliferative retinopathy ${ }^{27,28}$. Studies have now demonstrated that vascular endothelial growth factor (VEGF) probably has a major role in mediating proliferative retinopathies ${ }^{29-32}$. VEGF is an angiogenic protein and a potent vasopermeability factor that stimulates retinal endothelial cell growth in vitro through activation of protein kinase $\mathrm{C}^{33}$ and has been identified in ocular fluids of patients with diabetes and other ocular disorders ${ }^{29,32}$. Concentrations of VEGF are higher in patients with active proliferative disease and lower in patients with inactive disease af- ter scatter laser photocoagulation or spontaneous remission of proliferative retinal disease ${ }^{29}$. The concentration of VEGF is also increased in the anterior segment of eyes with active rubeosis iridis ${ }^{29}$. Additionally, VEGF action increases retinal vascular permeability in vivo, with obvious implications for diabetic macular oedema ${ }^{23}$.

Inhibitors of VEGF used in animal models of ischaemia-induced retinal neovascularization reduced the neovascular response ${ }^{30,31,35}$. Pharmaceutical suppression of VEGF activity is a potential novel treatment for diabetic retinopathy ${ }^{33-36}$. Clinical trials are now being initiated to test pharmaceutical action of oral and local anti-VEGF agents with the hope of preventing retinal neovascularization, diabetic macular oedema and other vasoproliferative retinopathies, without the retinal destruction inherent in current therapeutic regimens.

Studies by Smith et $\mathrm{al}^{37,38}$ have shown that interactions between IGF-1 and the IGF-1 receptor are necessary for induction of maximal neovascularization by VEGF. Therefore IGF-1 plays an essential role in angiogenesis as a permissive agent. Previous controlled clinical trials showed that pituitary ablation could improve diabetic retinopathy and indicated that therapeutic success was correlated with the magnitude of GH decrease ${ }^{39}$. In order to avoid the high rates of morbidity and mortality from hypopituitarism and because the beneficial effects of hypopituitarism might be due to the cessation of GH secretion, therapies to block the actions of $\mathrm{GH}$ were initiated. A small-scale trial of octreotide, a somatostatin analogue, showed that at high doses, the agent may retard the progression of the vision-threatening disease ${ }^{40}$. A larger trial, involving 30 clinical centres, is in progress. Another three-month, open-label trial with pegvisomant did not cause regression of the new retinal vessels in patients with 'non-high-risk' proliferative diabetic retinopathy, although plasma levels of IGF-1 decreased by $50 \%{ }^{41}$.

\section{GENERAL GUIDELINES}

Until modalities are in place to prevent or cure diabetic retinopathy, the emphasis must be on excellent diabetic control and on early identification, careful follow-up and timely laser photocoagulation or vitrectomy, or both, in patients with diabetic retinopathy. Proper care will result in reduction of personal 
suffering for those involved, as well as substantial cost savings for the patients and their families.

All diabetic patients should be informed of the possibility of the development of retinopathy with or without symptoms and the associated threat of visual loss. The natural course and treatment of diabetic retinopathy should be discussed and the importance of routine examination stressed. Patients should be informed of the possible relationship between the level of control of diabetes and the subsequent development of ocular and other medical complications. Patients should be informed that diabetic nephropathy, as manifested by proteinuria, requires aggressive early treatment to avoid superimposed retinopathy (and the possible associated risk of neovascular glaucoma). The association of joint contractures, hypertension, cardiovascular disease, elevated lipid levels and neuropathy with onset and progression of diabetic retinopathy should be discussed.

Diabetic women contemplating pregnancy should have a complete eye examination before conception. Pregnant women with diabetes should have their eyes examined early and in each trimester of pregnancy and should have a postpartum examination 3 to 6 months after delivery. Since pregnancy may exacerbate existing retinopathy and may be associated with hypertension, careful medical and ocular observation during pregnancy is crucial. Retinopathy status may have an impact on the method of delivery, and close communication among the various members of the medical team is essential.

Patients with diabetic retinopathy, even in its mildest form, must be informed of the availability and benefits of early and timely laser photocoagulation therapy in reducing the risk of visual loss

\section{CONCLUSIONS}

In its earliest stages, diabetic retinopathy usually causes no symptoms. Visual acuity may be excellent and, on evaluation and diagnosis, a patient may deny the presence of retinopathy. It is crucial at this stage for a patient's physician to initiate a careful programme of evaluation, education and follow-up of any ocular condition.

Great progress has been made in improving the outcome of patients with diabetic retinopathy. It must be underlined, however, that the key for substantial further improvement of the outcome lies in its early detection and proper management and an excellent control of hyperglycemia.

\section{REFERENCES}

1. Early Treatment Diabetic Retinopathy Study Report Number 9, 1991 Early photocoagulation for diabetic retinopathy. Ophthalmology 98: 766-785.

2. Moloney JBM, Drury MI, 1982 The effect of pregnancy on the natural course of diabetic retinopathy. Am J Ophthalmol 93: 745-756.

3. Serup L, 1986 Influence of pregnancy on diabetic retinopathy. Acta Endocrinol 277: 122-124.

4. Phelps RL, Sakol P, Metzger BE, et al, 1986 Changes in diabetic retinopathy during pregnancy: Correlations with regulation of hyperglycemia. Arch Ophthalmol 104: 18061810.

5. The Kroc Collaborative Study Group, 1984 Blood glucose control and the evolution of diabetic retinopathy and albuminuria. N Engl J Med 311: 365-372.

6. Grunwald JE, Riva CE, Martin DB, et al, 1987 Effect of insulin-induced decrease in blood glucose on the human diabetic retinal circulation. Ophthalmology 94: 1614-1620.

7. Chase HP, Jackson WE, Hoops SL, et al, 1989 Glucose control in the renal and retinal complications of insulindependent diabetes. JAMA 261: 1155-1160.

8. Brinchmann-Hansen O, Dahl-Jorgensen K, Hanssen KF, et al, 1985 Effects of intensified insulin treatment on various lesions of diabetic retinopathy. Am J Ophthalmol 100: 644-653.

9. Krolewski AS, Canessa M, Warram JH, et al, 1988 Predisposition to hypertension and susceptibility to renal disease in insulin-dependent diabetes mellitus. $\mathrm{N}$ Engl J Med 318: 140-145.

10. Chew EY, Klein ML, Ferris FL III, et al, and the ETDRS Research Group, 1996 Early Treatment Diabetic Retinopathy Study Report Number 22. Association of elevated serum lipid levels with retinal hard exudates in diabetic retinopathy. Arch Ophthalmol 114: 1079-1084.

11. Stern MP, Patterson JK, Haffner SM, et al, 1989 Lack of awareness and treatment of hyperlipidemia in type II diabetes in a community survey. JAMA 262: 360-364.

12. Fong DS, Warram JH, Aiello LM, et al, 1995 Cardiovascular autonomic neuropathy and proliferative diabetic retinopathy. Am J Ophthalmol 120: 317-321.

13. Early Treatment Diabetic Retinopathy Study Report Number 12, 1991 Fundus photographic risk factors for progression of diabetic retinopathy. Ophthalmology 98: 823-833.

14. Early Treatment Diabetic Retinopathy Study Report Number 13, 1991 Fluorescein angiographic risk factors for progression of diabetic retinopathy. Ophthalmology 98: 834-840.

15. Browning DJ, McOwen MD, Bowen RM Jr, O’Marah TL, 2004 Comparison of the clinical diagnosis of diabetic 
macular edema with diagnosis by optical coherence tomography. Ophthalmology 111: 712-715.

16. Frank RN, Schulz L, Abe K, Iezzi R, 2004 Temporal variation in diabetic macular edema measured by optical coherence tomography. Ophthalmology 111: 211-217.

17. Panozzo G, Gusson E, Parolini B, Mercanti A, 2003 Role of OCT in the diagnosis and follow up of diabetic macular edema. Semin Ophthalmol 18: 74-81.

18. Gotzaridis EV, Lit ES, D'Amico DJ, 2001 Progress in Vitreoretinal Surgery for Proliferative Diabetic Retinopathy. Seminars in Ophthalmology 16: 31-40.

19. Michels R, 1981 Proliferative diabetic retinopathy: Pathophysiology of extraretinal complications and principles of vitreous surgery. Retina 1: 1-17.

20. Radetzky S, Walter P, Fauser S, Koizumi K, Kirchhof B, Joussen AM, 2004 Visual outcome of patients with macular edema after pars plana vitrectomy and indocyanine green-assisted peeling of the internal limiting membrane. Graefes Arch Clin Exp Ophthalmol (Epub ahead of print).

21. Asami T, Terasaki H, Kachi S, et al, 2004 Ultrastructure of internal limiting membrane removed during plasminassisted vitrectomy from eyes with diabetic macular edema. Ophthalmology 111: 231-237.

22. Massin P, Audren F, Haouchine B, et al, 2004 Intravitreal triamcinolone acetonide for diabetic diffuse macular edema: preliminary results of a prospective controlled trial. Ophthalmology 111: 218-225

23. Martidis A, Duker JS, Greenberg PB, et al, 2002 Intravitreal triamcinolone for refractory diabetic macular edema. Ophthalmology 109: 920-927.

24. Diabetes Control and Complications Trial Research Group, 1993 The effect of intensive treatment of diabetes on the development and progression of long-term complications in insulin-dependent diabetes mellitus . N Engl J Med 329: 977-986.

25. Association of glycaemia with macrovascular and microvascular complications of type 2 diabetes (UKPDS 35), 2000 prospective observational study. BMJ 321: 405-411.

26. Tight blood pressure control and risck of macrovascular and microvascular complication in type 2 diabetes: UKPDS 38, 1998 . BMJ 317: 703-712.

27. Michaelson IC, 1948 The mode of development of the vascular system of the retina, with some observations on its significance for certain retinal disease. Trans Ophthalmol Soc UK 68: 137-180.

28. Ashton N, 1957 Retinal vascularization in health and disease. Am J Ophthalmol 44: 7-24.

29. Aiello LP, Avery RL, Arrigg PG, et al, 1994 Vascular endothelial growth factor in ocular fluids of patients with diabetic retinopathy and other ocular disorders. N Engl J
Med 331: 1480-1487.

30. Amin RH, Frank RN, Kennedy A, et al, 1997 Vascular endothelial growth factor is present in glial cells of the retina and optic nerve of human subjects with nonproliferative diabetic retinopathy. Invest Ophthalmol Vis Sci 38: 36-47.

31. Pierce EA, Avery R, Folet ED, et al, 1995 Vascular endothelial growth factor/vascular permeability factor expression: A mouse model of retinal neovascularization. Proc Natl Acad Sci USA 92: 905-909.

32. Adamis AP, Miller JW, Bernal MT, 1994 Increased vascular endothelial growth factor levels in the vitreous of eyes with proliferative diabetic retinopathy. Am J Ophthalmol 118: 445-450.

33. Tilton RG, Kawamura T, Chang KC, et al, 1997 Vascular dysfunction induced by elevated glucose levels in rats mediated by vascular endothelial growth factor. J Clin Invest 99: 2192-2202.

34. Pu X, Aiello LP, Ishii H, et al, 1996 Characterization of vascular endothelial growth factor's effect on the activation of protein kinase $\mathrm{C}$, its isoforms and endothelial growth. J Clin Invest 98: 2018-2026.

35. Aiello LP, Bursell SE, Clermont A, et al, 1997 Vascular endothelial growth factor-induced retinal permeability is mediated by protein kinase $\mathrm{C}$ in vivo and suppresssed by an orally effective beta-isoform-selective inhibitor. Diabetes 46: 1473-1480.

36. Robinson GS, Pierce EA, Rook SL, et al, 1996 Oligodeoxynucleotides inhibit retinal neovascularization in a murine model of proliferative retinopathy. Proc Natl Acad Sci U S A 93: 4851-4856.

37. Smith LE, Kopchick JJ, Chen W, et al, 1997 Essential role of growth hormone in ischaemia-induced retinal neovascularization. Science 276: 1706-1709.

38. Smith LE, Shen W, Perruzzi C, et al, 1999 Regulation of vascular endothelial growth factor-dependent retinal neovascularization by insulin-like growth factor-1 receptor. Nat Med 5: 1390-1395.

39. Lundbaek K, Malmros R, Anderson HC, 1989 Hypophysectomy for diabetic angiopathy: a controlled clinical trial. In Symposium on the treatment of Diabetic Retinopathy (Public Health Service Publ. no. 1890)

40. Grant MB, Mames RN, Fitzgerald C, et al, 2000 The efficacy of octreotide in the therapy of severe nonproliferative and early proliferative diabetic retinopathy: a randomized controlled study. Diabetes Care 23: 504-509.

41. Growth Hormone Antagonist for Proliferative Diabetic Retinopathy Study Group, 2001 The effect of a growth hormone receptor antagonist drug on proliferative diabetic retinopathy. Opthalmology 108: 2266-2272. 